REPeC, Brasília, v. 10, n. 4, índice por títulos, Periódico Trimestral, digital e gratuito publicado pela Academia Brasileira de Ciências Contábeis

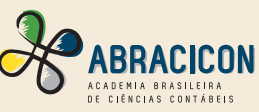
p. 469-470, out./dez. 2016

Disponível online em www.repec.org.br

\title{
ÍNDICE POR TÍTULOS - 2016
}

Adoção da IFRS no Brasil: Efeitos no Conservadorismo Contábil

Erivelto Fioresi de Sousa, Anderson Fioresi de Sousa, Gladyson Brommonschenkel

REPeC, Brasília, v. 10, n. 2, art. 1, p. 136-147, abr./jun. 2016

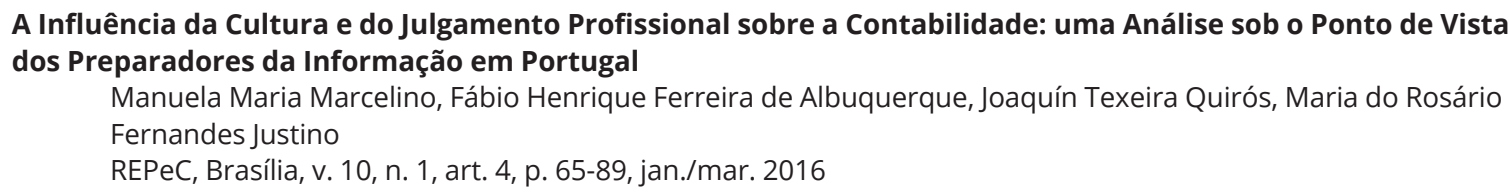

A Influência da Cultura e do Julgamento Profissional sobre a Contabilidade: uma Análise sob o Ponto de Vista dos Preparadores da Informação em Portugal

Manuela Maria Marcelino, Fábio Henrique Ferreira de Albuquerque, Joaquín Texeira Quirós, Maria do Rosário Fernandes Justino REPeC, Brasília, v. 10, n. 1, art. 4, p. 65-89, jan./mar. 2016

\author{
A Influência das Avaliações de Fornecedores na Rescisão de Contratos de Serviços de Exploração e Produção de \\ Petróleo e Gás no Brasil \\ Cleison Antonio Pinto, Danilo Soares Monte-Mor, Jedson Pereira Pinto \\ REPeC, Brasília, v.10, n. 1, art. 2, p. 25-45, jan./mar. 2016
}

\section{Análise da temática Contabilidade Gerencial na formação em Ciências Contábeis de IES mineiras à luz do Currículo Mundial e da Proposta Nacional do CFC/FBC}

Paula Mieko Oda Faria, Edvalda Araújo Leal REPeC, Brasília, v. 10, n. 2, art. 3, p. 163-180, abr./jun. 2016

Ciclo de Vida das Empresas, Book-Tax Differences e a Persistência nos Lucros

Antonio Lopo Martinez, Márcio Bassetti

REPeC, Brasília, v. 10, n. 2, art. 2, p. 148-162, abr./jun. 2016

Comitê de Auditoria: Adequação às Regras da SOX, Bacen, Susep e IBGC

Marina Schreiber de Abreu Siigor Sorrentino, Bruna Teixeira, Ernesto Fernando Rodrigues Vicente REPeC, Brasília, v. 10, n. 3, art. 1, p. 241-257, jun./set. 2016

Compromissos dos Contratos Psicológicos e Uso Diagnóstico dos Sistemas de Controle Gerencial Ivan Canan, Gilberto de Andrade Martins, Patrícia Oda Repec, Brasília, v. 10, n. 2, art. 4, p. 181-195, abr./jun. 2016

Consistência das Estratégias de Instituições de Ensino Superior: Um Estudo baseado na Percepção dos Stakeholders utilizando-se do Balanced Scorecard

Alexsandra Barcelos Dias, Valquíria Aparecida dos Santos, Aziz Xavier Beiruth REPeC, Brasília, v. 10, n. 4, art. 5, p. 431-448, out./dez. 2016

Critica Metodológica e Epistemológica de Pesquisas Contábeis Experimentais Publicadas no Brasil Paulo Frederico Homero Junior

REPeC, Brasília, v. 10, n. 2, art. 6, p. 220-233, abr./jun. 2016

Desempenho dos Alunos de Ciências Contábeis na Prova do Enade/2012: Uma Aplicação da Teoria da Resposta do Item

Raphael Vinicius Weigert Camargo, Rita de Cássia Correa Pepinelli Camargo, Dalton Francisco de Andrade,

Antonio Cezar Bornia

REPeC, Brasília, v. 10, n. 3, art. 6, p. 332-355, jul./set. 2016

Desempenho Financeiro e Divulgação de Informações sobre Recursos Humanos: uma Análise das Empresas do IBrX - 100

Gustavo Henrique Costa Souza, Luiz Antonio Félix Junior, Umbelina Cravo Teixeira Lagioia, João Gabriel

Nascimento de Araújo

REPeC, Brasília, v. 10, n. 1, art. 5, p. 90-105, jan./mar. 2016

Determinantes da Formação de Board Interlocking no Mercado de Capitais Brasileiro Flávio Ribeiro, Romualdo Douglas Colauto, Ademir Clemente REPeC, Brasília, v. 10, n. 4, art. 3, p. 398-415, out./dez. 2016

Fatores Determinantes para Adoção de Planos de Opções de Ações em Companhias Abertas Brasileiras Geovanne Dias de Moura, Edilson Sidnei Padilha, Tarcísio Pedro da Silva REPeC, Brasília, v. 10, n. 3, art. 3, p. 272-288, jul./set. 2016 
Fatores que Influenciam o Processo de Ensino-Aprendizagem sob a Perspectiva de Estudantes do Curso de

Ciências Contábeis: Análise em uma Instituição de Ensino Superior de Minas Gerais

Caroline Stéffani Santos Nério Pavione, Bruna Camargos Avelino, José Roberto de Souza Francisco REPeC, Brasília, v. 10, n. 2, art. 5, p. 196-219, abr./jun. 2016

Influências da Socialização Acadêmica no Desenvolvimento das Publicações Científicas em Contabilidade no

Brasil: Uma Análise dos Programas de Pós-Graduação Stricto Sensu

Flaviano Costa, Gilberto de Andrade Martins

REPeC, Brasília, v. 10, n. 3, art. 5, p. 314-331, jul./set. 2016

Influências de teorias Econômicas na Teoria Contábil: o caso da Função-Objetivo da Firma

Lineker Costa Passos, Aline Nogueira Bezerra, Antonio Carlos Coelho

REPeC, Brasília, v. 10, n. 4, art. 4, p. 416-430, out./dez. 2016

Informações Financeiras Ambientais: Diferença ente o Nível de Disclosure entre Empresas Brasileiras Janaina da Silva Ferreira, Suliani Rover, Denize Demarche Minatti Ferreira, José Alonso Borba REPeC, Brasília, v. 10, n. 1, art. 1, p. 5-24, jan./mar. 2016

Modelagem de Equações Estruturais com Mínimos Quadrados Parciais: Um Exemplo da Aplicação do $S m a r t P L S \circledR$ em Pesquisas em Contabilidade

João Carlos Hipólito Bernardes do Nascimento, Marcelo Alvaro da Silva Macedo

REPeC, Brasília, v. 10, n. 3, art. 4, p. 289-313, jul./set. 2016

O Impacto das Dimensões Culturais sobre a Prática Contábil no Brasil: um olhar a partir da Percepção dos

Operadores da Contabilidade

Bruno Jesus de Lima

REPeC, Brasília, v. 10, n. 4, art. 1, p. 363-379, out./dez. 2016

Os Benefícios Pessoais da Pós-Graduação Stricto Sensu: uma Análise na Percepção de Mestres em Contabilidade Tiago Guimarães Barth, Sandra Rolim Ensslin, Altair Borgert REPeC, Brasília, v. 10, n. 1, art. 6, p. 106-128, jan./mar. 2016

Os Impactos da Adoção de Metodologias Ativas no Desempenho dos Discentes do Curso de Ciências Contábeis

de Instituições de Ensino Superior Mineira

Cícero José Oliveira Guerra, Aridelmo José Campanharo Teixeira

REPeC, Brasília, v. 10, n. 4, art. 2, p. 380-397, out./dez. 2016

Os Indicadores Relativos à Gestão do Capital de Giro Antes e Depois da Adoção dos Padrões Internacionais de

Contabilidade no Brasil

Taís Duarte Silva, Gilberto José Miranda

REPeC, Brasília, v. 10, n. 3, art. 2, p. 258-271, jul./set. 2016

Processo de Implementação do IFRS: um ensaio teórico sobre as justificativas relacionadas a resistencias às mudanças organizacionais sob a teoria de Lewin

Camila Pereira Boscov, Gabriel Ribeiro Vieira Rezende

REPeC, Brasília, v. 10, n. 4, art. 6, p. 449-465, out./dez. 2016

Uso da Análise Hierárquica (AHP) para Identificação da Preferência de Peritos-Contadores Quanto ao Método de Avaliação de Sociedades em Perícias Contábeis

Claudio Roberto Caríssimo, Márcia Athayde Moreira, Martinho Maurício Gomes de Ornelas, Jersone Tasso

Moreira Silva

REPeC, Brasília, v. 10, n. 1, art. 3, p. 46-64, jan./mar. 2016 